\title{
Agravos clínicos decorrentes das arboviroses: uma revisão de literatura
}

\author{
Clinical injuries due arbovirus infections: a literature review \\ Condiciones clínicas derivadas de arbovirus: revisión de la literatura
}

Recebido: 18/01/2021 | Revisado: 20/01/2021 | Aceito: 15/02/2021 | Publicado: 23/02/2021

\author{
Julliana Ferrari Campêlo Libório de Santana \\ ORCID: https://orcid.org/0000-0002-7773-3398 \\ Universidade do Estado de Mato Grosso Carlos Alberto Reyes Maldonado, Brasil \\ E-mail: julliana.ferrari@unemat.br \\ Andressa Pereira Ronn \\ ORCID: https://orcid.org/0000-0003-4193-956X \\ Universidade do Estado de Mato Grosso Carlos Alberto Reyes Maldonado, Brasil \\ E-mail: andressa.ronn@unemat.br \\ Guilherme Nascimento Bezerra \\ ORCID: https://orcid.org/0000-0002-8445-8128 \\ Universidade do Estado de Mato Grosso Carlos Alberto Reyes Maldonado, Brasil \\ E-mail: guilherme.bezerra@unemat.br \\ Tatiana Lima da Silva Fernandes \\ ORCID: https://orcid.org/0000-0002-8061-0989 \\ Universidade do Estado de Mato Grosso Carlos Alberto Reyes Maldonado, Brasil \\ E-mail: mellima9@yahoo.es
}

\begin{abstract}
Resumo
As arboviroses classificam-se como um grupo de patologias causadas pelos denominados arbovírus, em especial o Aedes aegypti. No cenário nacional, as que ganham maior destaque são a Dengue, Febre amarela, Chikungunya e a Zika. O objetivo deste estudo é descrever os principais agravos clínicos decorrentes de arboviroses através de uma revisão de literatura. $\mathrm{O}$ artigo segue os preceitos do estudo exploratório, por meio de uma pesquisa bibliográfica, que é desenvolvida a partir de material já elaborado e divulgado em bases de dados. Os textos analisados demonstraram similaridades entre os sintomas das 4 arboviroses estudadas em casos leves ou iniciais, bem como a singularidade dos agravos clínicos de cada uma dessas doenças. As pesquisas recentes trazem nova compreensão da sintomatologia e das possíveis repercussões destas ao organismo, assim como de novas possibilidades de tratamento e posterior seguimento adequado ao paciente. O acompanhamento da evolução do paciente bem como a boa compreensão de sinais agravantes são vitais para a contenção de potenciais agravos clínicos. Ademais, os agravos observados acabam desenvolvendo fatores impactantes socioeconômicos, pelo grande prejuízo na manutenção da cadeia produtiva e pela debilitação dos pacientes.
\end{abstract}

Palavras-chave: Dengue; Febre amarela; Febre de Chikungunya; Infecção por Zika virus; Infecções por Arbovirus.

\begin{abstract}
Arboviruses are classified as a group of pathologies caused by denominated arbovirus, in particular Aedes aegypti. In the national scenario, the ones that gain more prominence are Dengue, Yellow fever, Chikungunya and Zika. The aim of this study is to describe the main clinical problems resulting from arboviruses through a literature review. The article follows the precepts of the exploratory study, through a bibliographic research, which is developed from material already elaborated and disseminated in databases. The analyzed texts showed similarities between the symptoms of the 4 arboviruses studied in mild or initial cases, as well as the uniqueness of the clinical conditions of each of these diseases. Recent research brings a new understanding of the symptoms and their possible repercussions to the body, as well as new possibilities for treatment and subsequent appropriate follow-up to the patient. Monitoring the patient's evolution as well as a good understanding of aggravating signs are vital for containing potential clinical problems. In addition, the injuries observed end up developing socioeconomic impact factors, due to the great damage in the maintenance of the production chain and the weakening of patients.
\end{abstract}

Keywords: Dengue; Yellow fever; Chikungunya fever; Zika Virus infection; Arbovirus infections.

\section{Resumen}

Los arbovirus se clasifican como un grupo de patologías causadas por los denominados arbovirus, en particular Aedes aegypti. En el escenario nacional, los que ganan más protagonismo son el Dengue, la Fiebre Amarilla, el Chikungunya y el Zika. El objetivo de este estudio es describir los principales problemas clínicos derivados de los arbovirus mediante una revisión de la literatura. El artículo sigue los preceptos del estudio exploratorio, mediante una búsqueda bibliográfica, que se desarrolla a partir de material ya elaborado y difundido en bases de datos. Los textos analizados 
mostraron similitudes entre los síntomas de los 4 arbovirus estudiados en casos leves o iniciales, así como la singularidad de las condiciones clínicas de cada una de estas enfermedades. Investigaciones recientes aportan una nueva comprensión de los síntomas y sus posibles repercusiones en el organismo, así como nuevas posibilidades de tratamiento y posterior seguimiento adecuado del paciente. El seguimiento de la evolución del paciente y un buen conocimiento de los signos agravantes son vitales para contener posibles problemas clínicos. Además, las lesiones observadas acaban desarrollando factores de impacto socioeconómico, debido al gran daño en el mantenimiento de la cadena productiva y al debilitamiento de los pacientes.

Palabras clave: Dengue; Fiebre Amarilla; Fiebre Chikungunya; Infección por el Virus Zika; Infecciones por Arbovirus.

\section{Introdução}

A modificação do ambiente por ações antrópicas relacionadas às atividades econômicas, proporcionou que muitos vetores, como os mosquitos, se tornassem sinantrópicos, favorecendo a transmissão ao homem. Na última década, tem-se observado a emergência de algumas doenças transmitidas por mosquitos vetores, especialmente as arboviroses. (Fauci \& Morens, 2012).

Os arbovírus (Arthropod-borne vírus) são assim designados não somente pela sua veiculação através de artrópodes, mas, principalmente, pelo fato de parte de seu ciclo acontecer nos insetos. São transmitidos aos humanos e outros animais pela picada de artrópodes hematófagos, especialmente mosquitos (Mourão et al., 2015).

As arboviroses são um dos principais problemas de saúde no mundo. A Organização Mundial da Saúde (OMS) estima que 80 milhões de pessoas se infectem anualmente, em 100 países, de todos os continentes, menos na Europa. Destes, 550 mil necessitam de hospitalização, e 20 mil morrem em consequência das arboviroses, principalmente da Dengue. (Camara, 2016).

O registro de arboviroses no Brasil surgiu no final do século XIX, com a primeira epidemia de Dengue. O mosquito Aedes aegypti tem sido um desafio para a saúde pública brasileira que, inicialmente, lidava apenas com a epidemia de Dengue e Febre Amarela. Atualmente esse mosquito, que também é o vetor da febre de Chikungunya e da febre Zika, aparece como um desafio alarmante para as autoridades sanitárias brasileiras e também do mundo, ao trazer sérios riscos à saúde da população (Camara, 2016).

A Dengue, a Febre Amarela, a febre de Chikungunya e a febre pelo vírus Zika são doenças de notificação compulsória e estão presentes na Lista Nacional de Notificação Compulsória de Doenças, Agravos e Eventos de Saúde Pública, sendo que a febre pelo vírus Zika foi acrescentada a essa lista apenas pela Portaria $n^{\circ}$ 204, de 17 de fevereiro de 2016, do Ministério da Saúde (Ministério da Saúde, 2016).

As manifestações clínicas de infecção por arbovírus podem variar desde a doença febril leve e indiferenciada a síndromes febris neurológicas, articulares e hemorrágicas. Com frequência, os quadros graves são conhecidos somente após circulação viral em extensas epidemias, muitas vezes mostrando impacto imprevisível na morbidade e mortalidade, enquanto a ocorrência, até então, restringia-se a casos isolados ou pequenos surtos (Donalisio et al., 2017).

A doença febril geralmente se apresenta com sintomas de gripe, como febre, cefaleia, dor retro-orbital e mialgia. A síndrome neurológica (Síndrome de Choque da Dengue - SCD) pode manifestar-se como mielite, meningite e/ou encefalite, com mudanças de comportamento, paralisia, paresia, convulsões e problemas de coordenação. A artralgia manifesta-se como exantema ou rash maculopapular, poliartralgia e poliartrite, enquanto que a síndrome hemorrágica (Febre Hemorrágica da Dengue - FHD) é evidenciada pelas petéquias, hemorragia e choque combinado com uma redução intensa de plaquetas (Donalisio et al., 2017).

O prejuízo econômico dessas novas arboviroses é alarmante, pois, apesar de a maioria dos pacientes infectados apresentar recuperação completa após a fase aguda da doença, alguns sintomas, como a forte artralgia do Chikungunya, podem durar algumas semanas ou até meses, prejudicando as atividades ocupacionais do infectado (Camara, 2016). 
A entrada desses arbovírus no Brasil, que já tem uma endemia de Dengue, pode ter como resultado uma sobrecarga nos serviços de saúde durante epidemias explosivas simultâneas. Muitos esforços têm sido realizados na intenção de diminuir a circulação de doenças transmitidas por vetores. Com exceção da Febre Amarela, a principal forma de combate se dá através do controle dos insetos vetores, visto que ainda não existe uma vacina eficiente para as outras arboviroses transmitidas pelo Aedes aegypti (Camara, 2016).

A taxa de letalidade dessas arboviroses é baixa, o que torna importante saber que a maioria dos óbitos e agravos são potencialmente evitáveis. No Brasil, não é a falta de protocolos que faz com que ocorra um elevado número de óbitos, mas a assistência inicial nem sempre adequada (Vita et al., 2009).

As doenças decorrentes de arboviroses têm um alto custo para a sociedade, estimado em cerca de 2,3 bilhões de reais só em 2016. Além dos custos econômicos e para a saúde pública, há um grande impacto social quando ocorrem epidemias, já que muitas vezes os serviços precisam interromper a assistência primária para os pacientes hospitalizados (Teich et al., 2017).

É necessário que se estude e se descreva os principais agravos decorrentes das arboviroses emergentes, para que se estabeleça fluxos de atendimento diferenciados e ágeis nos períodos endêmicos. Evitando a sobrecarga dos atendimentos de urgência e emergência e de erros no diagnóstico inicial. O presente artigo tem como objetivo descrever os principais agravos clínicos decorrentes de arboviroses através de revisão bibliográfica.

\subsection{Arboviroses mais comuns no Brasil}

\subsubsection{Dengue}

O vírus Dengue (DENV) é representado por quatro sorotipos, a saber, DENV-1 à DENV-4 e sua transmissão é feita pelo mosquito Aedes aegypti. A existência de mais de um sorotipo, DENV-1 e DENV-2, ocorreu por volta de 1940, e o DENV-3 e o DENV-4 foram primeiramente isolados durante epidemias nas Filipinas em 19568. Foi anunciada a descoberta de um novo sorotipo, o Dengue vírus tipo 5 (DENV-5), isolado de um surto na Malásia em 2007. Esse sorotipo pode estar circulando entre primatas não humanos e infecções humanas ainda não foram relatadas (Ferreira et al., 2009).

Estes vírus podem afetar pessoas de todas as idades, incluindo recém-nascidos, crianças, adultos e idosos, causando um espectro de doenças que vão desde a febre da Dengue até as formas mais graves de Dengue hemorrágica (DH) e Síndrome do choque da Dengue (SCD). Os sinais e sintomas incluem febre, dor retro-orbital, dor de cabeça intensa, mialgia, artralgia e manifestações hemorrágicas menores, como petéquias, epistaxe e sangramento gengival (Ferreira et al., 2009).

As primeiras células infectadas após a inoculação viral pela picada do mosquito são, provavelmente, as células dendríticas da pele. Após a replicação inicial e migração para os linfonodos, os vírus aparecem na corrente sanguínea (viremia) durante a fase febril aguda, geralmente por três a cinco dias. Considera-se que a liberação de citocinas, como resultado da infecção das células dendríticas, macrófagos e a ativação de linfócitos TCD4+ e TCD8+, desempenha um papel importante. Além disso, a liberação de interferon pelos linfócitos $\mathrm{T}$ pode estar intimamente relacionada à queda na contagem de plaquetas, pela supressão da atividade da medula óssea, o que gera sintomas como as petéquias espalhadas pelo corpo. Da corrente sanguínea, os vírus são disseminados a órgãos como fígado, baço, nódulos linfáticos, medula óssea, podendo atingir o pulmão, coração e trato gastrointestinal (Tauil, 2002).

A patogenia dos casos mais graves de Dengue (DH e SCD) ainda não é bem conhecida. Existem algumas hipóteses, tais como: reinfecção por um sorotipo diferente; aumento da permeabilidade vascular com extravasamento de plasma e coagulação intravascular, resultante da liberação de mediadores químicos pelos macrófagos/monócitos destruídos pela infecção; surgimentos de cepas mais virulentas após sucessivas passagens em mosquitos e seres humanos. O fenômeno de reinfecção por um segundo sorotipo foi validado in vitro e encontrou-se resultados concordantes in vivo testado em camundongos. Na reinfecção por um segundo sorotipo, a presença de vírus opsonizados pelos anticorpos que já foram 
formados, geram imunocomplexos que ativam o sistema complemento, e liberam mediadores químico. A lesão hepática provocada pela replicação viral nos hepatócitos compromete os fatores de coagulação, que associado à diminuição de plaquetas, pode ocasionar um quadro hemorrágico grave (Lopes et al., 2014; Naranjo-Gómez, 2019).

\subsubsection{Febre Amarela}

É uma doença de etiologia viral, de curta duração (máximo 12 dias), não contagiosa, causada por um vírus do gênero Flavivírus, família Flaviviridae. Pode apresentar infecções subclínicas e/ou leves, até formas graves e fatais. Na Febre Amarela urbana o homem é o único hospedeiro com importância epidemiológica (Tauil, 2010).

A fêmea do Aedes aegypti contrai o vírus através da ingestão de sangue do homem infectado e transmite o vírus picando o homem sadio. O período de incubação do vírus no homem pode variar de três a seis dias, e o vírus pode ser transmitido ao mosquito 24 ou 48 horas antes do aparecimento dos sintomas e até cinco dias após. No mosquito, o período de incubação varia de nove a doze dias; logo após, o vírus pode ser transmitido por toda a vida do mosquito (Tauil, 2010).

A série histórica do número de casos humanos confirmados de Febre Amarela urbana no Brasil apresenta aspecto irregular, com tendência estacionária, marcada por períodos endêmicos, caracterizados por casos isolados em indivíduos não vacinados, geralmente na região amazônica, intercalados por períodos epizoóticos e/ou epidêmicos, quando o vírus afeta principalmente populações de áreas com baixas coberturas vacinais, geralmente nas regiões Centro-Oeste, Sudeste e Sul do país. Desde 2014 o número de casos confirmados vem crescendo, notando se a reemergência do vírus (Ministério da Saúde, 2020).

O MS, analisando as evidências científicas disponíveis e as recomendações da Organização Mundial de Saúde sobre a duração da imunidade conferida pela vacina contra Febre Amarela, estabeleceu novas recomendações que já estão inseridas nos Calendários de Vacinação. Até abril de 2017, o Brasil adotava o esquema vacina de duas doses, sendo a segunda dose aplicada 10 anos depois da primeira dose. A partir de abril 2017 a vacina vem sendo aplicada em dose única (Ministério da Saúde, 2020).

\subsubsection{Chikungunya}

Chikungunya é uma doença de etiologia viral (Família Togaviridae, gênero Alphavirus), que é transmitida de pessoa para pessoa através da picada de mosquitos infectados - incluindo Aedes aegypti e Aedes albopictus. Estes mosquitos se infectam quando se alimentam de uma pessoa infectada com o vírus. O período de incubação do vírus Chikungunya no ser humano é de dois a dez dias, aproximadamente (Brito et al., 2016).

A maioria dos indivíduos infectados pelo CHIKV desenvolve sintomas e alguns estudos mostram que até $70 \%$ apresentam infecção sintomática. Esses valores são altos e significativos quando comparados às demais arboviroses. Dessa forma, o número de pacientes que necessitam de atendimento é elevado, gerando uma sobrecarga nos serviços de saúde (de Brito et al., 2016).

Os sinais e os sintomas são clinicamente parecidos com os da Dengue - febre de início agudo, dores articulares e musculares, cefaleia, náusea, fadiga e exantema. A principal manifestação clínica da Chikungunya que a difere são as fortes dores nas articulações e a persistência dos sintomas por semanas a meses. Após a fase aguda inicial, a doença pode evoluir em duas etapas subsequentes: fase subaguda e crônica (Brito et al., 2016).

Após o período de incubação, inicia-se a fase aguda ou febril, que dura até o décimo quarto dia. Alguns pacientes evoluem com persistência das dores articulares após a fase aguda, caracterizando o início da fase subaguda, com duração até 3 meses (Ministério da Saúde, 2015).

Quando os sintomas persistem por mais de 3 meses, inicia-se a fase crônica. Nesta fase, as manifestações clínicas 
incluem: exantema, vômitos, sangramento e úlceras orais, dor articular, edema e febre. Os casos graves e óbitos ocorrem com maior frequência em pacientes com comorbidades e em extremos de idade (Ministério da Saúde, 2015).

\subsubsection{Zika}

O vírus Zika foi isolado pela primeira vez em primatas em Uganda, na floresta Zika em 1947 - vem daí a sua denominação (Donalisio et al., 2017; Ramírez-rayón et al., 2018). Entre 1951 e 2013, evidências sorológicas em humanos foram notificadas em países da África, Ásia e Oceania. Nas Américas, o Zika vírus foi identificado unicamente na Ilha de Páscoa, território do Chile, no oceano Pacífico, a $3.500 \mathrm{~km}$ do continente no início de 2014. É um vírus RNA do gênero Flavivírus, família Flaviviridae e tem como vetor principal o mosquito Aedes aegypti (Kasprzykowski et al., 2020; VindasGuerrero \& Alfaro-Campos, 2018).

Estima-se que em maio de 2015 o vírus Zika chegou ao Brasil. Na ocasião, o MS declarou que o fato não apresentava maiores riscos, pois a doença não poderia ser fatal como a Dengue. No entanto, em outubro de 2015, o Zika vírus deixou de ser uma preocupação branda, e se tornou uma grande ameaça, quando foi associado, ainda que de forma hipotética, a casos de microcefalia em Pernambuco (Kasprzykowski et al., 2020).

Desde então, a incidência do vírus foi declarada pelo MS como Emergência em Saúde Pública de Importância Nacional, um mecanismo previsto para casos que demandem o emprego urgente de medidas de prevenção, controle e contenção de riscos, danos e agravos à saúde pública. Em dezembro do mesmo ano, a Organização Mundial da Saúde (OMS) emitiu alerta mundial, para seus mais de 140 países-membros reforçarem a vigilância ante o eventual crescimento de infecções provocadas pelo Zika vírus (Kasprzykowski et al., 2020).

Ainda em 2015, foi decretada situação de emergência em saúde pública de importância internacional. A associação do vírus às suspeitas de microcefalia fez com que a nova epidemia passasse a ser um novo acontecimento social, reforçando os sentimentos de imprevisibilidade, de insegurança e incerteza. Sendo essas características comuns a arboviroses endêmicas (Donalisio et al., 2017).

Inúmeras outras descobertas relacionadas ao vírus têm sido apresentadas, desde a confirmação do envolvimento com os casos de microcefalia e com a Síndrome de Guillain-Barré, até a identificação de transmissão por vias sexual e vertical (Ministério da Saúde, 2017; Rodrigues \& Grisotti, 2019; Russo et al., 2017; Ministério da Saúde, 2016). Em junho de 2020, foi publicado um estudo com a descoberta uma nova linhagem do vírus circulando no Brasil, a africana, nunca antes identificada no país, o que levanta a possibilidade de uma reemergência da epidemia (Kasprzykowski et al., 2020).

\section{Metodologia}

O artigo segue os preceitos da revisão sistemática, que consiste em uma pesquisa científica em bases de dados bibliográficos de textos científicos. A busca é guiada por critérios confiáveis e previamente estabelecidos, os mesmos utilizados para uma investigação científica tradicional. Compõe-se, basicamente, de quatro etapas: formulação do problema e objetivo, coleta de dados, análise dos dados, interpretação e divulgação (Pereira, 2014).

A busca bibliográfica ocorreu no mês de março e abril de 2020, na Base de Dados Bibliográficos Especializada na Área de Enfermagem do Brasil (BDENF), na Scientific Electronic Library Online (SciELO), na Literatura Latino-Americana em Ciências de Saúde (LILACS), PubMed® e os seguintes descritores foram aplicados: "Dengue", "Febre Amarela", "Febre de Chikungunya", "Vírus Zika", "Infecções por Arbovírus".

Após a busca, foram encontrados 478 artigos e os critérios de inclusão foram: pesquisas publicadas nos idiomas inglês, português ou espanhol, disponíveis online e gratuitas e, estudos a partir 2015. Como critérios de exclusão: trabalhos que não contemplavam a temática ou não respondiam à questão orientadora. Ao final foram selecionados 42 estudos. Além 
disso, para fins epidemiológicos, também foram utilizados manuais divulgados pelo Ministério da Saúde acerca desses temas.

Foi realizado a leitura exploratória, leitura seletiva e também registro das informações extraídas. Seguiu-se por analisar as informações, de forma a obter as respostas ao problema da pesquisa. Por fim, os resultados foram discutidos a partir do referencial teórico relativo à temática do estudo.

\section{Resultados e Discussão}

Após delimitação do tema, foram selecionados os artigos para discussão e os mesmos foram divididos em 4 categorias:

\subsection{Dengue}

Os primeiros sintomas da dengue são inespecíficos e podem ser confundidos com os de outras doenças febris presentes na região. As manifestações iniciais mais frequentes são febre, mialgia, artralgia e cefaleia (Matta et al., 2016; Cavalli et al., 2019).

Um estudo feito na Colômbia em 2013 revelou que de acordo com a gravidade, os pacientes com dengue sem sinais de alarme foram a maioria, seguidos por aqueles com sinais de alarme e dengue grave. Tal achado é semelhante a um estudo realizado no Brasil - Goiás- também em 2013, onde a dengue clássica, isto é, sem sinais de alarme, predominou entre os casos (Matta et al., 2016; Nascimento et al., 2015).

Escobar (2018) e seus colaboradores analisaram os sinais de alerta em pacientes cubanos internados com dengue. Na maioria dos pacientes, o número crescente de hematócrito se destacou e, metade destes apresentaram também plaquetopenia, seguido por dor abdominal, lipotimia, prostração e sangramentos mucosos. A apresentação média de qualquer sinal de alarme foi em 4,72 dias do início dos sintomas (Escobar et al., 2018).

Entretanto, no estudo de Carrión (2018), os sinais de alerta aparecem precocemente, entre o $2^{\circ}$ e o $3^{\circ}$ dia de evolução da doença, com predomínio de hipotensão grave, dor abdominal e vômito. Plaquetopenia também foi relatado por este autor em parte dos pacientes, e não houve relação direta entre este achado e as manifestações hemorrágicas, já que valores plaquetários normais também expôs episódios de sangramento (Carrión et al., 2018).

As diferenças entre um ou outro sinal de alerta da dengue podem ser atribuídas a vários fatores relacionados às características epidemiológicas de cada região. Ainda, independente da forma clínica da doença, as manifestações de gravidade podem aparecer, em média, em 42 horas após os sinais de alerta serem evidentes. A forma grave SCD, por exemplo, pode aparecer 24-48 horas após o início dos sinais de alerta, causando danos graves aos órgãos podendo evoluir a óbito (Escobar et al., 2018).

\subsection{Febre Amarela}

O quadro clínico típico caracteriza-se por manifestações de insuficiência hepática e renal, tendo em geral apresentação bifásica, com um período inicial prodrômico (infecção) e um toxêmico. O período prodrômico dura cerca de 3 dias, tem início súbito e sintomas inespecíficos como febre, calafrios, cefaleia, lombalgia, mialgias generalizadas, prostração, náuseas e vômitos. Após esse período, geralmente, ocorre declínio da temperatura e diminuição dos sintomas, provocando uma sensação de melhora no paciente. Dura poucas horas, no máximo um a dois dias (Ministério da Saúde, 2017).

Por fim, inicia-se o período toxêmico, quando reaparece a febre, a diarreia e os vômitos têm aspecto de borra de café. Instala-se quadro de insuficiência hepatorrenal caracterizado por icterícia, oligúria, anúria e albuminúria, acompanhado de manifestações hemorrágicas: gengivorragia, epistaxe, otorragia, hematêmese, melena, hematúria, sangramentos em locais de punção venosa e prostração intensa, além de comprometimento do sensório, com obnubilação mental e torpor, com evolução 
para coma e morte. O pulso torna-se mais lento, apesar da temperatura elevada. Essa dissociação pulso-temperatura é conhecida como sinal de Faget (Ministério da Saúde, 2017).

O melhor tratamento para a Febre Amarela persiste em ser de ordem preventiva por intermédio da imunização, uma vez que não há tratamento específico para a doença já instalada. Em casos graves, a taxa de mortalidade é de até 50\%, o que exige maior cuidado e atenção com os pacientes afetados. É de suma importância que o diagnóstico seja rápido, visando promover maior contenção de danos do vírus ao organismo (de Oliveira \& Ferreira, 2018; Medeiros, 2018).

Estima-se que o fígado (juntamente com o rim, baço, coração e cérebro), possa sofrer demasiado dano com a doença devido a destruição de suas células específicas - os hepatócitos - o que, por sua vez, desencadeia a necrose hepática por coagulação (Oliveira \& Ferreira, 2018; Medeiros, 2018).

Pacientes graves são submetidos a monitorização constante, ressuscitação volêmica e reposição de fatores de coagulação (os quais estão diminuídos devido a danos ao fígado). Apesar da carência de estudos que comprovem a eficácia da técnica, transplantes hepáticos podem ser utilizados como última opção terapêutica (Oliveira \& Ferreira, 2018; Medeiros, 2018).

\subsection{Chikungunya}

De acordo com o MS, além da dor articular incapacitante febre de início súbito, e surgimento de intensa poliartralgia, geralmente acompanhada de dores nas costas, rash cutâneo - casos graves e óbitos relacionados a Chikungunya têm sido relatados (Ministério da Saúde, 2017).

Há poucas informações sobre o estado clínico do paciente em casos fatais. As informações disponíveis sugerem que a partir dos 53 anos, sintomas respiratórios, neurológicos e cardiovasculares são os mais agravantes. Justifica-se a associação entre a gravidade dos sintomas a idade avançada à presença de outras patologias (Cerbino-Neto et al., 2020).

A evolução da doença pode ser classificada em três tipos: clássico (o qual abrange os sintomas característicos da doença sem demais agravantes), severo e neurológico. O subtipo severo abrange um complexo comprometimento do sistema, incluindo fígado, pulmões e até mesmo os olhos decorrente de uma resposta inflamatória intensa. Ainda dentro desse subtipo, os danos ao sistema cardiovascular, apesar de não muito discutidos, podem ser relevantes. Estudos relatam que o CHIKV adentra os miócitos e gera dano às fibras musculares provocando resposta inflamatória que leva a danos secundários por reação de hipersensitividade e necrose, todavia, sem sinais típicos de infarto (Rodriguez-Morales et al., 2017).

Os pacientes com danos cardiovasculares podem enfrentar três fases distintas: na fase de pródromo, onde apesar de não haver sinais clínicos, há presença de cardiomegalia que pode ser identificada com radiografia simples ou ecocardiograma; $\mathrm{Na}$ ausculta cardíaca, há presença de ritmo galopante. Posteriormente a isso, há início de uma segunda fase caracterizada por arritmias, onde os danos aos miócitos já são demasiados não possibilitando o funcionamento correto do sistema cardiovascular. O último estágio caracteriza-se por quadro de insuficiência cardíaca. Edema pulmonar e insuficiência renal (condição que acompanha $20 \%$ de pacientes com sintomas cardíacos) podem ser consequências de choque cardiogênico (Rodriguez-Morales et al., 2017).

Os sintomas neurológicos são encontrados em menos de $1 \%$ dos pacientes. No entanto, achados neurológicos, quando identificados, podem ser letais, pois são frutos diretos da infecção viral, e não correlações sistêmicas. As manifestações neurológicas mais comuns incluem a síndrome de Guillain-Barré, meningoencefalite e encefalite desmielinizante aguda; em crianças, as manifestações mais comuns são crises convulsivas. Manifestações menos frequentes, como a neurite óptica e a mielite transversa podem ser encontradas (Ministério da Saúde, 2017).

Mulheres que adquirem Chikungunya no período gestacional podem transmitir o vírus a recém-nascidos por via transplacentária ou transmissão perinatal. A taxa de transmissão, neste período, pode chegar a aproximadamente 50\% dos 
casos, destes, cerca de $90 \%$ podem evoluir para formas graves (Oliveira \& Ferreira, 2018).

\subsection{Zika}

Historicamente, o ZIKAV apresenta-se como uma doença de comportamento benigno, de baixíssima virulência e letalidade, com sintomas como mialgia, artralgia e edema articular, febre, conjuntivite, erupção cutânea maculopapular, prurido, hipertrofia ganglionar, cefaleia e prostração (Cunha et al., 2020; Araujo et al., 2016). O último aumento de 20 vezes na epidemia brasileira de microcefalia, de 2014 a 2015, levou as autoridades de saúde pública a postularem que a causa pode ser infecção por ZIKAV em mulheres grávidas (Vindas-Guerrero \& Alfaro-Campos, 2018; Ministério da Saúde, 2017). De acordo com uma análise preliminar de pesquisa realizada pelo MS, o maior risco de microcefalia e malformações está associado à infecção durante o primeiro trimestre da gravidez (Garcia \& Duarte, 2016). Em novembro de 2015, foi comprovada a relação entre o aumento do número de recém-nascidos com microcefalia e a Zika. Isso se deu por meio da identificação do vírus no líquido amniótico de gestantes infectadas que tiveram seus bebês diagnosticados com microcefalia ainda intra útero. Confirmou-se, então, que o vírus era responsável pelas alterações encontradas, tanto a microcefalia, como outros agravos (Ministério da Saúde, 2017). Estudos entre grupos de pesquisa demonstraram que o vírus, por ter acentuado neurotropismo, parece prejudicar o desenvolvimento do tecido nervoso, o que justificaria os inúmeros efeitos da infecção nesse sistema (Ministério da Saúde, 2017). Ele causa danos diretos nas células progenitoras neuronais da zona ventricular e subventricular, ocasionando uma diminuição da produção neuronal e da espessura da zona ventricular que ocorre por um mecanismo de freio do ciclo celular ou por um aumento da apoptose. Respostas imunes à infecção também podem estar envolvidas (Arroyo et al., 2018). Há uma relação direta entre o período da gestação no qual houve o acometimento viral e a gravidade e a extensão das alterações observadas, de modo que, quanto mais avançada a gestação, mais brandos são os danos ao feto (Nunes et al., 2016).

A infecção pelo vírus Zika durante o desenvolvimento embrionário e fetal possui características distintas daquelas observadas na microcefalia decorrente de outras infecções congênitas, que tem sido descrito como Síndrome Congênita do Zika Vírus (SCZV) (Albuquerque et al., 2018; Teixeira et al., 2020). Os achados observados na SCZV são variáveis de acordo com a gravidade, além de possuir uma sintomatologia diversa, incluindo artrogripose, malformação da coluna vertebral, ventriculomegalia, microcalcificações no tecido neurológico cerebral, hipotrofia cortical, hidropisia fetal e malformações oculares e disrupção do crescimento sequencial cerebral (Ministério da Saúde, 2017; Albuquerque et al., 2018). Ademais, foram relatas deficiências do desenvolvimento psicomotor e físico, alterações do Sistema Nervoso Central (SNC), como a epilepsia, deformidades do sistema osteoarticular e deficiências visuais e auditivas (Brito et al., 2020). Exames de imagem são úteis por evidenciar, além de microcefalia, microcalcificações periventriculares e corticais, hipoplasia de vernix cerebelar, em alguns casos, lisencefalia compatível com padrão de infecções congênitas (Ministério da Saúde, 2017). Os relatos de ver calcificações no cérebro fetal e placenta foram documentados usando ultrassonografia, sendo este o exame de escolha pré e pós-natal para a investigação de possíveis anormalidades do desenvolvimento neurológico (Nunes et al., 2016; Lima Neto et al., 2016). Os relatos envolvendo acometimentos dos olhos incluem atrofia macular e lesões maculares e perimaculares com atrofia do nervo óptico (Oliveira \& Vasconcelos, 2016). Há relatos de caso evidenciando morte fetal seguida de aborto espontâneo e posterior confirmação de acometimento pela SCZV (Rivadeneyra-Espinar et al., 2019).

No segundo trimestre de 2015, foi identificado um surto de casos neurológicos relacionados à infecção por esse vírus no Brasil, atingindo diversos estados e centenas de pessoas. Destacou-se por apresentar alguns casos graves, morte e sequelas motoras permanentes (Russo et al., 2017). Os primeiros casos de acometimento neurológico relacionados ao ZIKV surgiram inicialmente na Polinésia, em 2013, com relatos de casos de Síndrome de Guillain-Barré (SGB) pós-epidemia (Araujo et al., 2016; Malta et al., 2017). 
Outros agravos da infecção pelo ZIKV incuem encefalomielite disseminada aguda, neurite óptica, meningite e meningoencefalite (Araujo et al., 2016; Malta et al., 2017). Também foram reportados acometimentos não neurológicos, tais quais perda auditiva transitória, hipotensão e sintomas geniturinários (Vindas-Guerrero \& Alfaro-Campos, 2018).

A SGB trata-se se de uma polirradiculoneuropatia imunomediada, frequentemente precedida por uma infecção (Ramírez-rayón et al., 2018; Nóbrega et al., 2018), sendo a complicação mais comum do ZIKV relacionada ao sistema nervoso. Manifesta-se, em geral, após o aparecimento dos primeiros sintomas sistêmicos da doença (Zunt, 2017). Essa síndrome costuma se iniciar por meio de distúrbios sensoriais simétricos os quais acometem inicialmente a porção distal dos membros, podendo evoluir para plegia, diminuição ou ausência dos reflexos tendinosos profundos, disfunção autonômica e da bexiga, disfagia orofaríngea, visão dupla, dificuldade de movimentação ocular e paralisia facial (Vindas-Guerrero \& AlfaroCampos, 2018; Zunt, 2017), além da presença característica de dissociação celuloproteica no líquido cefalorraquidiano (LCR) (Azevedo et al., 2016; Parra et al., 2016). Pode, outrossim, apresentar comprometimento cardiovascular e respiratório, demandando suporte avançado. O tempo de início dos sintomas após a infecção é de 6 a 10 dias (Zunt, 2017). Um estudo de casos chamou atenção por demonstrar uma mortalidade mais baixa da SGB associada ao ZIKV, quando comparada à SGB esporádica (Ramírez-rayón et al., 2018; Zunt, 2017).

\section{Conclusão}

As manifestações clínicas decorrentes das arboviroses são muito semelhantes, incluindo sinais e sintomas como febre, mialgia, artralgia e cefaleia. A dengue clássica é predominante entre os casos de dengue, porém a SCH e a FHD são potencialmente fatais. O acompanhamento da evolução do paciente bem como a boa compreensão de sinais agravantes é vitais para a contenção de potenciais agravos clínicos. É válido destacar que que o diagnóstico precoce da Febre Amarela é vital, visto que os danos ao organismo podem ser contidos significativamente.

Acompanhar as gestantes provavelmente infectadas pelo vírus Zika é importante, tendo em vista as potenciais consequências graves resultantes da infecção congênita, em especial a microcefalia e outras anomalias neurológicas.

As arboviroses, apesar de serem antigas no cenário nacional, não devem ser tratadas com negligência e a atualização referente a seu manejo e tratamento deve ser sempre uma constante no cenário da saúde, uma vez que agravos - como os causados pelo vírus Chikungunya - são raros, todavia, não devem ser descartados como diagnóstico. Ademais, os agravos observados acabam desenvolvendo fatores impactantes socioeconômicos, pelo grande prejuízo na manutenção da cadeia produtiva e pela debilitação dos pacientes. Reforça-se a necessidade da manutenção de campanhas e outras medidas preventivas para a diminuição da circulação do vetor Aedes aegypti.

Sugere-se também que, com o avanço das pesquisas e a descoberta de novas informações acerca dessas patologias, sejam realizados novos estudos a fim de sintetizar e divulgar aspectos relevantes na prática clínica que assegurem um cuidado efetivo ao paciente.

\section{Referências}

Albuquerque, M. F. P. M., Souza, W. V., Araújo, T. V. B., Braga, M. C., Miranda-Filho, D. B., Ximenes, R. A. A., Filho, D. A. M., Brito, C. A. A., Valongueiro, S., Melo, A. P. L., Brandão-Filho, S. P., \& Turchi Martelli, C. M. (2018). The microcephaly epidemic and Zika virus: Building knowledge in epidemiology. Caderno de Saúde Pública, 34(10), e00069018. https://doi.org/10.1590/0102-311x00069018 
Azevedo, R. S. S., Araujo, M. T., Martins Filho, A. J., Oliveira, C. S., Nunes, B. T. D., Cruz, A. C. R., Nascimento, A. G. P. A. C. et al. (2016). Zika virus epidemic in Brazil. I. Fatal disease in adults: Clinical and laboratorial aspects. Journal of Clinical Virology, 85, 56-64. https://doi:10.1016/j.jcv.2016.10.024

Brito, C. A. A., von Sohsten, A. K. A., de Sá Leitão, C. C., de Brito, R. de C. C. M., De Azevedo Valadares, L. D., da Fonte, C. A. M., de Mesquita, Z. B., Cunha, R. V., Luz, K., Leão, H. M. C., de Brito, C. M., \& Frutuoso, L. C. V. (2016). Pharmacologic management of pain in patients with Chikungunya: A guideline. Revista da Sociedade Brasileira de Medicina Tropical, 49(6), 668-679. https://doi.org/10.1590/0037-8682-0279-2016

Camara, T. N. (2016). Arboviroses emergentes e novos desafios para a saúde pública no Brasil. Revista de Saúde Pública., 50(36). https://doi.org/10.1590/S1518-8787.2016050006791

Carrión, G., Castillo, J. B., Céspedes, M. E. G. \& Bell, M. J. G. (2018). Aspectos clínico-epidemiológicos en pacientes con dengue y signos de alarma. Medisan, 22(7): 540-51. http://scielo.sld.cu/pdf/san/v22n7/1029-3019-san-22-07-540.pdf

Cavalli, F.S., Seben, J. T., Busato, M. A., Lutinski, J. A. \& Andrioli D. C. (2019) Controle do Vetor Aedes Aegypti e Manejo dos Pacientes com Dengue. Revista de pesquisa, cuidado é fundamental, 11(5): 1333-39. https://doi.org/10.9789/2175-5361.2019.v11i5.1333-1339

Cerbino-Neto, J., Mesquita, E. C., Amancio, R. T., \& Do Brasil, P. E. A. A. (2020). Events preceding death among chikungunya virus infected patients: A systematic review. Revista da Sociedade Brasileira de Medicina Tropical, 53, 1-11. https://doi.org/10.1590/0037-8682-0431-2019

Cunha, L. S., Medeiros, W. R., Lima Junior, F. A. V., \& Pereira, S. A. (2020). Relationship between social inequality indicators and the spatial distribution of zika virus cases. Ciência \& Saúde Coletiva, 25(5), 1839-1850. https://doi.org/10.1590/1413-81232020255.34642019

Donalisio, M. R., Freitas, A. R. R., \& Zuben, A. P. B. Von. (2017). Arboviruses emerging in Brazil: challenges for clinic and implications for public health. Revista de Saúde Pública, 51(30). https://doi.org/10.1590/S1518-8787.2017051006889

Escobar, O. E. T, Olivera, T. M. G., Yéndez, N. V. E., Rubio, D. G. \& Peraza O. C. (2018). Signos de alarma en pacientes cubanos con dengue según nueva clasificación revisada de la Organización Mundial de la Salud. Medisan, 22(8), 707-19. http://scielo.sld.cu/pdf/san/v22n8/1029-3019-san-22-08-707.pdf

Fauci, A. S. \& Morens, D. M. (2012). The perpetual challenge of infectious diseases. New England Journal of Medicine, 366(5), 454-461. https://doi.org/10.1056/NEJMra1108296

Ferreira, B. J., Souza, M. F. M., Filho A. M. S., Carvalho, A. A. (2009). Evolução histórica dos programas de prevenção e controle da dengue no Brasil. Ciência \& Saúde Coletiva, 14(3), 961-72. https://doi.org/10.1590/S1413-81232009000300032

Garcia, L. P., \& Duarte, E. (2016). Evidências da vigilância epidemiológica para o avanço do conhecimento sobre a epidemia do vírus Zika. Epidemiologia e Serviços de Saúde, 25(4), 679-681. https://doi.org/10.5123/S1679-49742016000400001

Hamad, G. B. N. Z., Souza, K. V. (2020). Síndrome congênita do Zika vírus: conhecimento e forma da comunicação do diagnóstico. Texto \& Contexto Enfermagem, 29, 1-14. https://doi.org/10.1590/1980-265X-TCE-2018-0517

Kasprzykowski, J. I., Fukutani, K. F., Fabio, H., Fukutani, E. R., Costa, L. C., Andrade, B. B., \& Queiroz, A. T. L. (2020). A recursive sub-typing screening surveillance system detects the appearance of the ZIKV African lineage in Brazil: Is there a risk of a new epidemic? International Journal of Infectious Diseases, 96, 579-581. https://doi.org/10.1016/j.ijid.2020.05.090

Lima Neto, A. S., Nascimento, O. J., Sousa, G. S., \& Lima, J. W. O. (2016). Dengue, zika e chikungunya - desafios do controle vetorial frente à ocorrência das três arboviroses - parte II. Revista Brasileira em Promoção da Saúde, 29(4), 463-470. https://doi.org/10.5020/18061230.2016.p305

Lopes, N., Linhares, R. E. C. \& Nozawa, C. (2014). Características gerais e epidemiologia dos arbovírus emergentes no Brasil. Revista Pan-Amazônica de Saúde, 5(3), 55-64. https://doi.org/10.5123/S2176-62232014000300007

Malta, J. M. A. S., Vargas, A., Leite, P. L. E., Percio, J., Coelho, G. E., Ferraro, A. H. A., Cordeiro, T. M. O., Dias, J. S., \& Saad, E. (2017). Síndrome de Guillain-Barré e outras manifestações neurológicas possivelmente relacionadas à infecção pelo vírus Zika em municípios da Bahia, 2015. Epidemiologia e Serviços de Saúde, 26(1), 9-18. https://doi.org/10.5123/S1679-49742017000100002

Matta, L., Barbosa, M. M. \& Morales-Plaza, C. D. (2016). Caracterización clínica de pacientes que consultaron por dengue en un hospital de tercer nivel en Cali, Colombia. Biomédica, 36(1), 133-39. https://doi.org/10.7705/biomedica.v36i1.2627

Ministério da Saúde. (2015). Febre de Chikungunya manejo clínico Febre de chikungunya: manejo clínico. Secretaria de Vigilância em Saúde. http://portalarquivos.saude.gov.br/images/pdf/2015/fevereiro/19/febre-de-chikungunya-manejo-clinico.pdf

Ministério da Saúde. (2016). Nota Informativa da Transmissão Sexual do Zika Vírus. Secretaria de Vigilância em Saúde. http://portalarquivos.saude.gov.br/images/pdf/2016/maio/10/nota-informativa-transmissao-sexual-zika-sas-svs.pdf

Ministério da Saúde. (2016). Portaria No 204 - Lista Nacional de Notificação Compulsória de Doenças, Agravos e Eventos de Saúde Públicos e Privados em todo o território nacional. Diário Oficial Da União. http://nhe.fmrp.usp.br/wp-content/uploads/2017/02/doencas_notificacoes_compulsorias.pdf

Ministério da Saúde. (2017). Vírus Zika no Brasil. Secretaria de Vigilância em Saúde. https://sistemas.mre.gov.br/kitweb/datafiles/SaoFrancisco/ptbr/file/Fact_Sheet_Zika_Virus_Marco16.pdf

Minstério da Saúde. (2017). Manejo Clínico Chikungunya. Ministério Da Saúde. https://bvsms.saude.gov.br/bvs/publicacoes/chikungunya_manejo_clinico.pdf

Ministério da Saúde. (2020). Situação epidemiológica da febre amarela no monitoramento $2019 / 2020$. Boletim Epidemiológico. https://www.saude.gov.br/images/pdf/2020/janeiro/15/Boletim-epidemiologico-SVS-01.pdf

Ministério da Saúde. (2020). Anexo v - instrução normativa referente ao calendário nacional de vacinação 2020 vacina BCG vacina hepatite B (recombinante). https://www.saude.gov.br/images/pdf/2020/marco/04/Instru----o-Normativa-Calend--rio-Vacinal-2020.pdf 
Medeiros, E. A. S. (2018). Desafios para o controle e tratamento da febre amarela no Brasil. Acta Paulista de Enfermagem, 31(2), 3-6. https://doi.org/10.1590/1982-0194201800017

Mourão, M. P. G., Bastos, M. S., Figueiredo, R. M. P., Gimaque, J. B. L., Alves, V. C. R., Saraiva, M. G. G., Figueiredo, M. L. G., Ramasawmy, R, Nogueira, M. L. \& Figueiredo, L. T. L. (2015). Arboviral diseases in the Western Brazilian Amazon: a perspective and analysis from a tertiary health \& research center in Manaus, State of Amazonas. Revista da Sociedade Brasileira de Medicina Tropical, 48 (1), 20-26. https://doi.org/10.1590/0037-8682-0133-2013

Naranjo-Gómez, J. S., Castillo-Ramírez, J. A., Velilla- Hernández, P. A. \& Astaño-Monsalve, D. M. (2019). Inmunopatología del dengue: importancia y participación de los monocitos y sus subpoblaciones. Iatreia, 32(3), 204-16. https://doi.org/10.17533/udea.iatreia.09

Nascimento, L. B., Oliveira, P. S., Magalhães, D. P., França, D. D. S., Magalhães, A. L. S., Silva, J. B., Silva, F. P. A. \& Lima D. M. (2015). Caracterização dos casos suspeitos de dengue internados na capital do estado de Goiás em 2013: período de grande epidemia. Epidemiologia e Serviços de Saúde, 24(3), 47584. https://doi.org/10.5123/S1679-49742015000300013

Nóbrega, M. E. B., Araújo, E. L. L., Wada, M. Y., Leite, P. L. E., Dimech, G. S., \& Pércio, J. (2018). Surto de síndrome de Guillain-Barré possivelmente relacionado à infecção prévia pelo vírus Zika, Região Metropolitana do Recife, Pernambuco, Brasil, 2015. Epidemiologia e Serviços de Saúde, 27(2), e2017039. https://doi.org/10.5123/S1679-49742018000200016

Nunes, M. L., Carlini, C. R., Marinowic, D., Neto, F. K., Fiori, H. H., Scotta, M. C., Zanella, P. L. Á., Soder, R. B., \& da Costa, J. C. (2016). Microcephaly and Zika virus: a clinical and epidemiological analysis of the current outbreak in Brazil. Jornal de Pediatria, 92(3), 230-240. https://doi.org/10.1016/j.jpedp.2016.04.001

Oliveira, C. S., \& Vasconcelos, P. F. C. (2016). Microcephaly and Zika virus. Jornal de Pediatria, 92(2), 103-105. https://doi.org/10.1016/j.jpedp.2016.02.013

Oliveira, G. M. M., \& Ferreira, R. M. (2018). Yellow fever and cardiovascular disease: An intersection of epidemics. Arquivos Brasileiros de Cardiologia, 110(3), 207-210. https://doi.org/10.5935/abc.20180041

Parra, B., Lizarazo, J., Jiménez-Arango, J. A., Zea-Vera, A. F., González-Manrique, G., Vargas, J., Angarita, J. A., Zuñiga, G., Lopez-Gonzalez, R., Beltran, C. L., Rizcala, K. H., Morales, M. T., Pacheco, O., Ospina, M. L., Kumar, A., Cornblath, D. R., Muñoz, L. S., Osorio, L., Barreras, P., \& Pardo, C. A. (2016). Guillain-Barré syndrome associated with Zika virus infection in Colombia. New England Journal of Medicine, 375(16), 1513-1523. https://doi.org/10.1056/NEJMoa1605564

Pereira, M. G. (2014). Artigos científicos: como redigir, publicar e avaliar. Guanabara Koogan.

Ramírez-rayón, E. M., Ávalos-ríos, J. M., García-jiménez, F. J., Blancas-cervantes, J. M., García-cuevas, E., Matadamas-hernández, N., \& López-velázquez, D. F. (2018). Medicina Interna de México, 34(5), 667-677. https://doi.org/10.24245/mim.v34i5.1778

Rivadeneyra-Espinar, P. G., Venegas-Esquivel, G. A., Díaz-Espinoza, C. M., Pérez-Robles, V. M., González-Fernández, M. I., \& Sesma-Medrano, E. (2019). Zika como causa de aborto espontáneo en zonas endémicas. Boletín médico del Hospital Infantil de México, 76(4), 193-197. https://doi.org/10.24875/bmhim.19000116

Rodriguez-Morales, A. J., Alvarez, M. F., Bolívar-Mejía, A., \& Ramirez-Vallejo, E. (2017). Cardiovascular involvement and manifestations of systemic Chikungunya virus infection: A systematic review. F1000Research, 6, 1-22. https://doi.org/10.12688/f1000research.11078.1

Rodrigues, R. R. N., \& Grisotti, M. (2019). Comunicando sobre Zika: recomendações de prevenção em contextos de incertezas. Interface - Comunicação, Saude, Educação, 23, 1-14. https://doi.org/10.1590/interface.190140

Russo, F. B., Jungmann, P., \& Beltrão-Braga, P. C. B. (2017). Zika infection and the development of neurological defects. Cellular Microbiology, 19(6), 1-6. https://doi.org/10.1111/cmi.12744

Tauil P.L. (2002) Aspectos críticos do controle do dengue no Brasil. Ciência \& Saúde Coletiva, 18(3): 867-71. doi: 10.1590/S0102-311X2002000300030

Tauil, P. L. (2010). Aspectos críticos do controle da febre amarela no Brasil. Revista de Saúde Pública, 44(3), 555-558. https://doi.org/10.1590/s003489102010005000014

Teich, V., Arinelli, R. \& Fahham, L. (2017) Aedes aegypti e sociedade: o impacto econômico das arboviroses no Brasil. Jornal Brasileiro de Economia da Saúde, 9(3): 267-276. doi: 10.21115/JBES.v9.n3.p267-76

Teixeira, G. A., Dantas, D. N. A., Carvalho, G. A. F. de L., da Silva, A. N., Lira, A. L. B. de C., \& Enders, B. C. (2020). Analysis of the concept of the zika virus congenital syndrome. Ciência \& Saúde Coletiva, 25(2), 567-574. https://doi.org/10.1590/1413-81232020252.30002017

Vindas-Guerrero, S., \& Alfaro-Campos, G. C. (2018). Caso de infección por virus Zika con alteración neurológica. Acta Médica Costarricense, 60(3), 136138. http://www.scielo.sa.cr/scielo.php?script=sci_arttext\&pid=S0001-60022018000300136\&lng=en\&tlng=es

Vita, W. P., Nicolai, C. C. A., Azevedo, M. B., Souza, M. F. \& Baran, M. (2009). Dengue: Alertas Clínicos e laboratoriais da evolução grave da doença. Revista da Sociedade Brasileira de Clínica Médica, 7, 11-14. http://files.bvs.br/upload/S/1679-1010/2009/v7n1/a11-14.pdf

Zunt, J. R. (2017). Neurologic manifestations of Zika virus infection Manifestaciones neurológicas de la infección por el virus zika. Anales de la Facultad de Medicina, 78(1), 83-87. https://doi.org/10.15381/anales.v78i1.13027 